\title{
Knowledge of food habit and other daily habit are the determinants of health status: A study among the students of Chattogram regions
}

\author{
Abdullah Al-Mamun ${ }^{1}$, Pabitra Debnath ${ }^{1}$, Farida Siddika ${ }^{1}$, Mohammed Jahedul Islam ${ }^{2, *}$
}

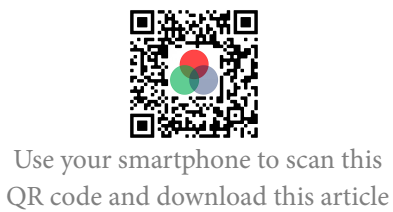

${ }^{1}$ Department of Genetic Engineering and Biotechnology, University of Chittagong

${ }^{2}$ Department of Public Health, University of Creative Technology Chittagong

Correspondence

Mohammed Jahedul Islam, Department of Public Health, University of Creative Technology Chittagong

Email: jahedkamal54@gmail.com

History

- Received: 2019-07-20

- Accepted: 2019-09-25

- Published: 2019-10-22

DOI

https://doi.org/10.15419/ajhs.v5i2.456

\section{Check for updates}

Copyright

(c) Biomedpress. This is an openaccess article distributed under the terms of the Creative Commons Attribution 4.0 International license.

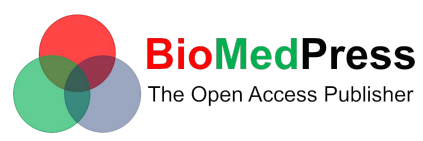

\begin{abstract}
Background: Health is wealth. Success, happiness, development, and almost everything of life depend largely on good health condition. Health status of each individual varies on age, gender, food habits, physical activities, lifestyle, ethnicity and culture. To ensure a prosperous future, students' health needs to be taken care of as they are the boatmen of any nation. Objectives: To uphold the awareness regarding health education, daily activities, food habits and health status among the student community across Chattogram regions of Bangladesh. Methods: After ensuring ethical approval, 651 students were randomly selected from different schools, colleges and universities across Chattogram region. The data were collected, compiled, analyzed and prepared. In this study, $62 \%$ male $(n=405)$ and 38\% female $(n=246)$ students were enrolled. Results: Awareness of health issues was found mostly in university students while this was rare among teenagers. Body Mass Index (BMI) among teenagers was found more fluctuated and was comparatively stable after teenage. Consciousness of cigarette smoking was found appreciable, but regular physical activity awareness should be increased more. The number of frequent internet users was not appreciable. Conclusion: Enrolled students were from different areas across Chattogram regions of Bangladesh, where some might stay with parents, some with other relatives in distant places and in academic hostels. The students were from different religious beliefs, culture, ethnicity, and from rural or coastal areas. Based on the mentioned categories of the students' origins, their food choices, daily habits, lifestyles and health related awareness could be different.

Key words: Students, Good health, food habits, physical activities, BMI, age, hygiene awareness
\end{abstract}

\section{INTRODUCTION}

According to WHO (2005), overweight and obesity are defined as abnormal or excessive fat accumulation that may impair health condition. BMI is a sample index that is commonly used to classify overweight and obesity in adults. BMI is defined as a person's weight in kilograms divided by the square of his height in meters $\left(\mathrm{Kg} / \mathrm{m}^{2}\right)^{1}$. WHO (2002) and FAO (2004) showed that 852 million people were undernourished worldwide with most ( 815 million) living in developing countries, confirming the increasing figure of undernourished people ${ }^{2}$. Factors that are correlated with obesity include age, gender, ethnicity, culture, diet, lifestyle and lack of physical activity ${ }^{3-7}$. Overweight is one of the most serious risk factors for both developed and developing countries (WHR report, 2002 $)^{8}$. Obesity is related with increasing morbidity and mortality, and also a major risk factor for noncommunicable diseases such as cardiovascular disease, stroke, diabetes mellitus, musculoskeletal disorders and cancers, which were the leading causes of death in $2012^{1,9}$. Physical activities including routine daily activities, exercises and active sports that are designed to improve body fitness are highly recommended. A minimum of $30-60$ minutes of moderate physical activity per day in children has been found significant to maintain health benefits ${ }^{10,11}$. Physical activities and exercises are known to be highly beneficial for all age groups. The habits of physical activities and exercises are found favorable to those people who are students for better metabolism and absorption of nutrients.

Consuming fast food is an alarming issue. The rates of fast food consumption are high among secondary, higher secondary and university students. Changing lifestyle is responsible for fast food consumption ${ }^{12}$. Other reasons including food choice, price, availability, flavor, hanging out with friends are noticeable ${ }^{13}$. Childhood obesity and eating junk food have become a global epidemic both in developed and developing countries. High socioeconomic status is significantly associated with junk food consumption among teenagers ${ }^{4}$. The main aim of nutrition plans is to gain regions. Asian J. Health Sci.; 5(2):10. 
proper and necessary nutrition to conduct a healthy life ${ }^{14}$. Educational institutes play an important role in providing the knowledge about nutritional status and practices to the students and mass community ${ }^{14}$. Physical exercises improve health by developing bone quality, strengthening muscles, enhancing the activity of cardiovascular system and decreasing depression and anxiety ${ }^{5,6}$.

Nutrition deficiency at any stage can cause serious results for cognitive development by reducing learning ability, poor concentration in studies and impaired school performances ${ }^{8}$. Consuming fast foods raises cholesterol levels in human body, as a result, body fat increases, which is fatal for heart. Fast food contains high sugar, saturated fat, salt, and high calories which may lead to early development of obesity and cardiovascular diseases in children. It is necessary to provide nutritional education and promote healthy eating habits and to raise awareness about bad impacts of junk foods ${ }^{15}$. Several studies provide evidences that students away from home worsen their food habits ${ }^{16}$. Good dietary practices are more frequent among students, who have more physical education than those who do not have physical education. Mary Story and Michael D Resnick (2000) studied the eating habits of teenagers and showed that the majority of students agreed to the fact that they are not "too big a bother" ${ }^{17}$. Fruits and vegetables are widely recommended for health promoting properties and dietary fibers. Fruits and vegetables contain high content of vitamins such as Vit-A and Vit-C, Minerals, electrolytes and antioxidants ${ }^{7}$. Consumption of fruits and vegetables is recognized both for cancer and cardiovascular diseases ${ }^{18-21}$.

Irregular life styles at early ages like students may cause severe impact on fertility and reproductivity. Male infertility treatment is one of the challenging tasks in developing countries given the nature of tradition and superstitions of professed confidentiality. From time immemorial women infertility is mainly considered ashuman infertility which is a fault and fanatic attitude ${ }^{22}$. Infertility is a major concern within family and society that affects couples. About $20 \%$ men around the world suffering from infertility that causes a serious concern for public health ${ }^{23}$. There are several risk factors that are directly or indirectly linked to male infertility in Bangladesh including age, occupational exposure, alcohol, caffeinated beverages, smoking, psychological stress and certain environment and lifestyle factors ${ }^{22}$. Drinking caffeinated beverages may impede fertility in men. More than three cups of tea daily are linked with decreased fertility in man $^{24}$. Researchers found that smoking is associated with man's fertility in three ways: the quality of sperm, ability to have sexual intercourse and libido state. The sperm quality of smokers is comparatively poorer than non-smokers and smoker's sperm is not properly formed. Furthermore, nicotine is the main component of tobacco, which lowers the chance of becoming pregnant ${ }^{25}$. Research has shown that smoking can minimize a man's fertility both directly and indirectly. Another chemical carbon monoxide that was found in cigarettes can reduce a man's testosterone levels, which has a negative impact for fertility ${ }^{25,26}$.

Using computer, mobile phone, internet is an epoch event in this modern era and exploring social media through internet has significant role to develop a better understanding of technologies and have impact on health communication ${ }^{27}$. The student community is largely dependent on internet for their study purpose. Recent studies say that increasing internet use and exploring social media are not uniformly distributed across age groups. Health communication programs, which are now using social media, must firstly consider the age of the targeted population to ensure important messages delivered to the audiences ${ }^{27}$. Social scientists observed that, electronic social media and direct participation of internet users are increasing, in which the importance of health communication programs was highlighted and efforts was made to use social media to enhance the impacts on public health ${ }^{28-31}$. Recent studies found that the relationships between social media and health have made conflicting consequences ${ }^{32}$. Sedentary activities such as watching TV and playing video games are familiar, resulting in less energy expenditure, poor eating habits and increased energy consumption ${ }^{33-35}$. Social media may be a good place to relate with healthy eating habits. Social media create person's individual profile that helps to communicate with one another and build a network among people ${ }^{33,34}$. It is also used as a tool for providing health care programs and services, education, research, intervention and treatment ${ }^{33-40}$. Spending time with computer is positively correlated with overweight ${ }^{41}$. A study reported that the majority of cell phone users started since teenage, adults under 30 prefer to use laptop, young adults and teenagers are fond of using mp3 players than other adults. People of 30 and over 30 years old are less likely to play mobile games compared to the younger age $^{23}$. Gender, education and income are co-related with using internet. Men are using internet comparatively more often than women. Behavioral changes are found in internet use ${ }^{42}$.

This study was solely conducted to uphold the awareness or consciousness regarding health education or health-based knowledge, daily activities, food habits 
and health status among the students of different places across Chattogram regions of Bangladesh.

\section{METHODS}

\section{EXPERIMENTAL DESIGN AND} SAMPLING

This community based cross-sectional study was carried out among students of different places across Chattogram area. A total of 651 students joined in this study were required to provide written consent. Students were randomly selected from primary, secondary, higher secondary and university students from 11 to over 30 years of age. The students were categorized or divided into 5 groups according to age range of $11-15,16-20,21-25,26-30$ and > 30 years. Regular and active students were included in this study. The data collections were carried out through a standard Questionnaire format, which was relevant to the study for evaluating information.

\section{DURATION OF THE STUDY}

The total duration of the study including ethical permission, data collection, statistical analysis, compiling results and total presentation of the study was approximately six months and the time duration was from November 2018 till April 2019.

\section{ETHICAL APPROVAL}

The ethical approval had been issued and the recommendations had been followed accordingly. Letter Reference No: UCTC/off-order/Eth-com/VII (II)/2019/007

\section{DATA COLLECTION}

In this study, the survey was designed and the interrogations were categorized into 10 parts and the Questionnaire was consisted of 47 questions. The questionnaire was designed on fast food consumption, balance diet maintenance, BMI, fruits and vegetables consumption, internet using rate, regular physical activity, nutrition-based knowledge and smoking awareness according to age and gender.

\section{MEASUREMENTS AND DATA ANALYSIS}

BMI was calculated by "BMI calculator" application. In this study, BMI was used to measure students health status as weight in kilogram divided by height in meter square $(\mathrm{BMI}=\mathrm{kg} / \mathrm{m} 2)$. Consumption of fast food was measured because it is associated with overweight and obesity. Questions such as "Do you maintain balanced diet?" were made to know health consciousness and other related issues. All the data were analyzed by Microsoft excel 2016 for the graphical representation. Statistical analyses were performed to frame the data in graph or chart forms.

Questionnaire:

1. Age

2. Gender

3. BMI

4. Regular fruits and vegetable consumption: Yes/no/don't know

5. Fast food consumption: Regular/sometimes/very rare

6. Balance diet maintenance: Regular/ Not always/ Never

7. Using internet: Regular/ Sometimes/ Rarely

8. Physical activity practices: Sometimes/ Often/ Very rarely

9. Nutrition based knowledge: Sufficient/ Average/ Below average

10. Smoking based awareness: Sufficient/ Average/ Not allowed etc.

\section{RESULTS}

The research was conducted on 651 students where $62 \%$ was male and $38 \%$ was female (Figure 1). And the percentage of students within 11-15 years of age was $32 \%, 16-20$ years of age was $22 \%, 21-25$ years of age was $32 \%, 26-30$ years of age was $7 \%$ and $>30$ years of age was $7 \%$ respectively (Figure 2 ).

In this study, 56\% students maintained normal body weight, $31 \%$ students were underweight, and $13 \%$ of students overweight in 11-15 years of age range. In the age range of 16-20 years, the percentage of underweight, normal and overweight were $14 \%, 67 \%$, and $19 \%$ respectively. $80 \%$ maintained normal body weight in 21-25 years of age range and in same age range 6\% was found underweight and $14 \%$ was found overweight. $4 \%$ of students was found underweight in age range of $26-30$ years, $79 \%$ of students maintained normal body weight and $17 \%$ of students was overweight. On the other hand, the highest percentage of overweight students was observed in $>30$ age's student's group and the percentage were $53 \%$, where $43 \%$ maintained normal body weight and $4 \%$ was found underweight (Figure 3).

Among the populations of this study, 50\% students consumed fast food occasionally, 39\% students rarely consumed, and $11 \%$ students were regular fast food consumers (Figure 4).

In this study, most of the students were fond of eating fruits and vegetables with interest. Among them 66 percent students in 21-25 years of age group, who 


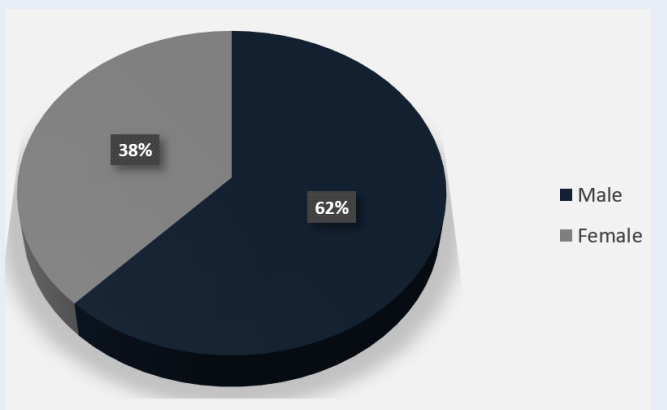

Figure 1: Ratio of Male and Female Students.
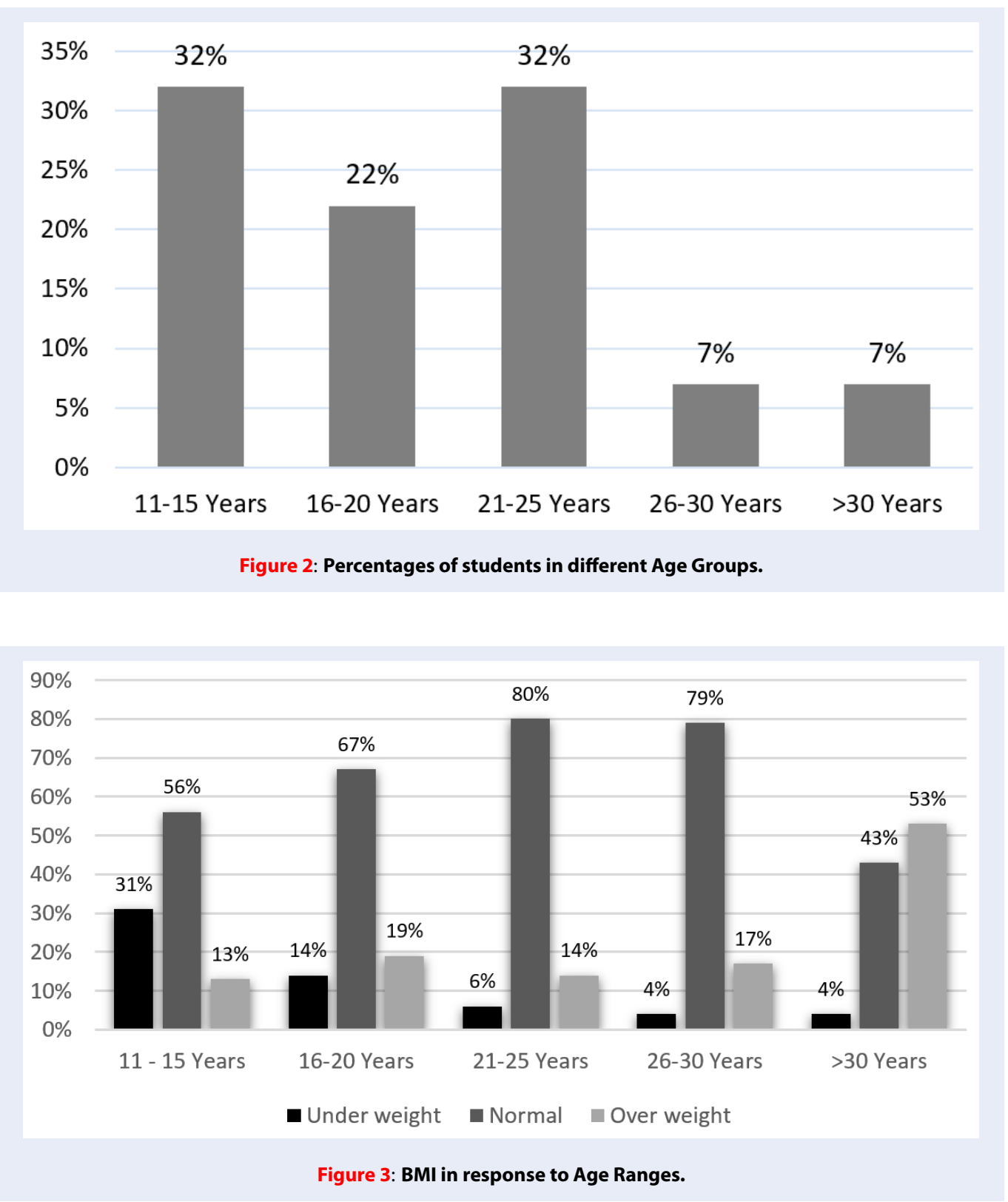


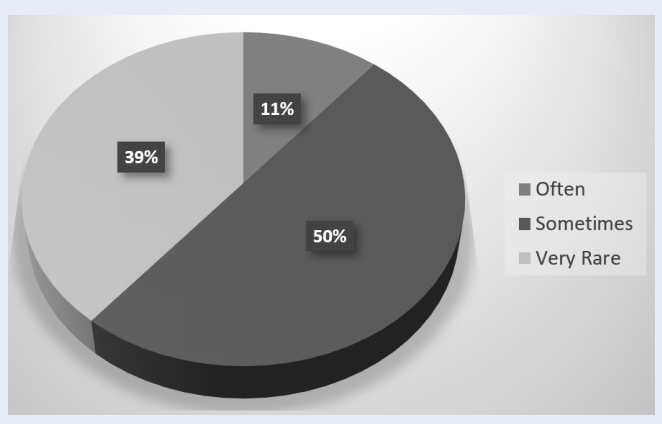

Figure 4: Rate of Fast Food Consumption.

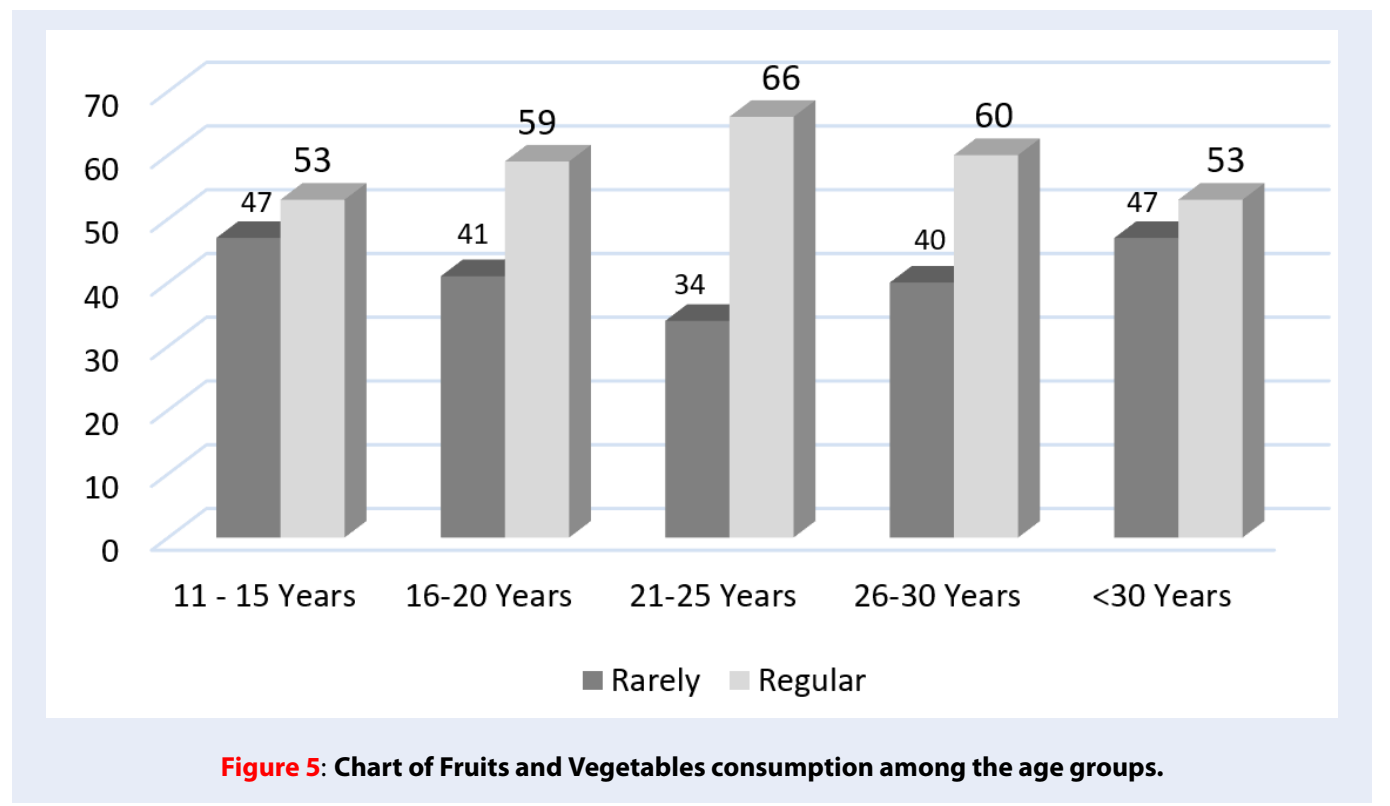

took fruits and vegetables regularly. 60 percent students in 26-30 years of age group used to consume regularly. In the 16-20 years of age group, the value was 59 percent, and regular consumption in both age ranges of 11-15 years and $>30$ years took around 53 percent (Figure 5).

The conducted study shows that, maximum students could not maintain their balanced diet regularly. The regular diet maintenance percentages were found $29 \%, 36 \%, 37 \%, 34 \%$, and $40 \%$ respectively among the individual age groups as 11-15 years, 16-20 years, 2125 years, $26-30$ years and $>30$ years. The irregular diet maintenance percentages was $65 \%, 52 \%, 53 \%, 51 \%$, and $53 \%$ respectively, while the percentages of those, who never maintained balanced diet were $6 \%, 12 \%$, $10 \%, 15 \%$, and $7 \%$ respectively (Figure 6).

Physical activities were not also maintained homogeneously among the student communities in this study. In age range of $11-15$ years, about $16 \%$ performed physical activities occasionally, $63 \%$ regularly and $21 \%$ rarely performed physical activities. In age range of 16-20 years, 57\% students did exercise regularly, $32 \%$ occasionally and $11 \%$ rarely performed physical activities. In the age range of 21-25 years old, $40 \%$ of students performed exercise occasionally, 53\% performed regularly and 7\% rarely did exercise. $60 \%$ of the students in age range of $26-30$ years often found, $28 \%$ found sometimes and $12 \%$ found very rarely. On the other hand, in $>30$ years student's group $45 \%$ sometimes found, $51 \%$ often found and $4 \%$ found very rarely (Figure 7).

Nutrition based awareness was sufficiently present among all age groups. Maximum percentage was $83 \%$ of student, which was found in age group of 26-30, $70 \%$ was found in $>30$ years of age, $61 \%$ in $21-25$ years of age range, $60 \%$ in $11-15$ years of age, and in $59 \%$ of the students between 16-20 years of age (Figure 8). 


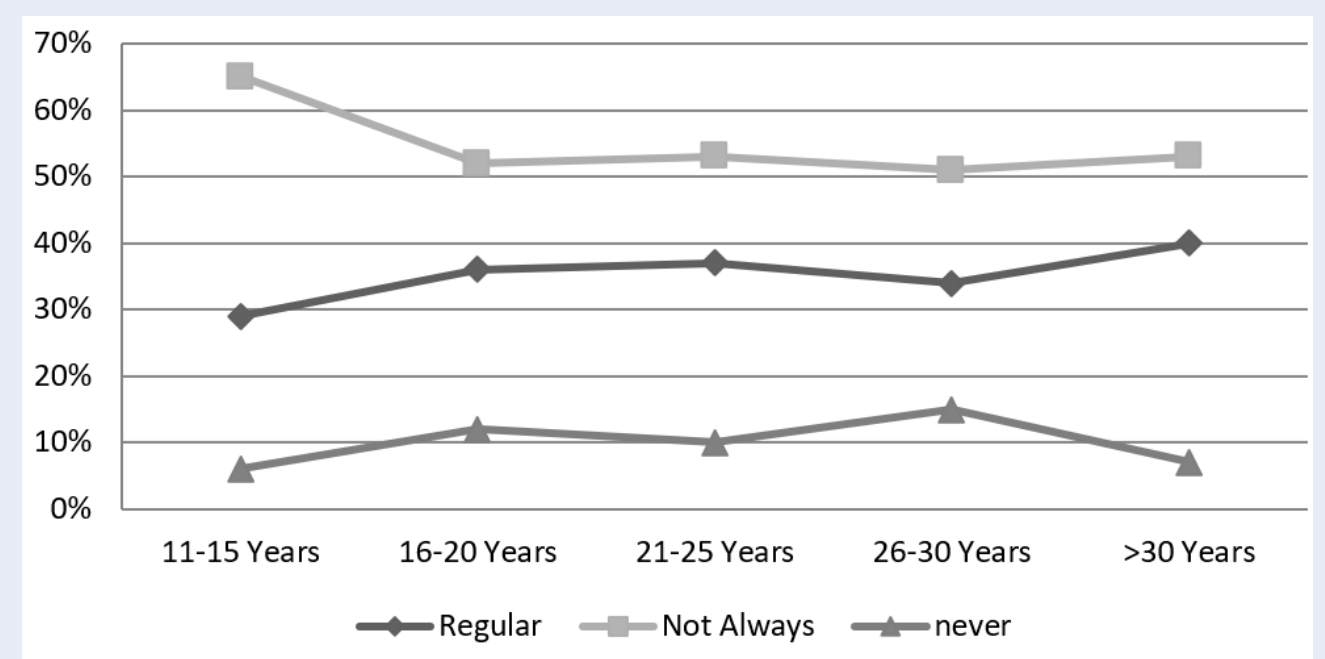

Figure 6: Percentages of maintaining balanced diet among the student age groups.

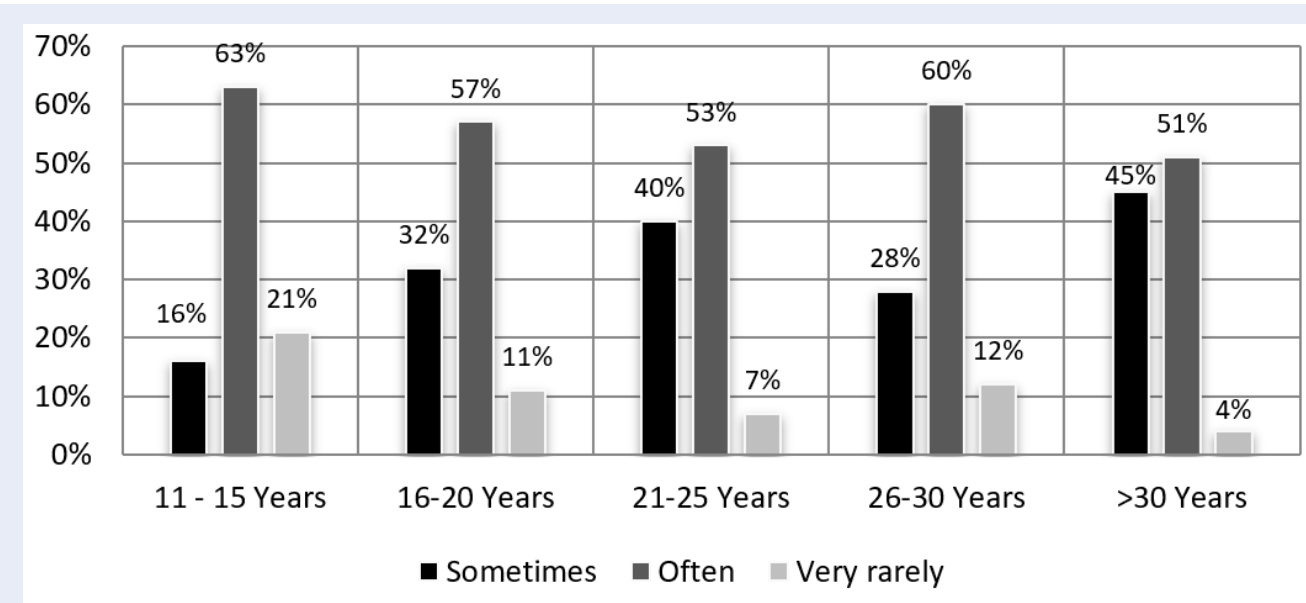

Figure 7: Percentages of Physical Activities among the age groups.

The result shows that $68 \%$ of students of the total community were well acknowledged about the bad effects of cigarette smoking; on the other hand, $6 \%$ of the students had no idea about the health effects by cigarette smoking, while $26 \%$ students had average idea about cigarette smoking and its bad impacts (Figure 9).

Internet is being used as an essential tool in education, research, entertainment, social communication media, playing games, watching movies or listening to music, searching for healthcare information and treatments. In this study the number of internet users was found satisfactory among all age groups. But in age group of 16-20 years $22 \%$ students found rare internet users, in 21-25 years of age group 17\% found rare internet users and $32 \%$ was found as rare internet users in $>30$ years of age group that were remarkable (Figure 10).

\section{DISCUSSION}

The study was conducted on 651 students altogether, among them, 404 (62\%) students were males and 247 (38\%) were females. Students were randomly selected from primary, secondary, higher secondary and university students and the students were from 11 to 30 years of age range, where some students were found who were $>30$ years of age. The students were categorized or divided into 5 groups according to age range of $11-15,16-20,20-25,26-30$ and $>30$ years. According to the Body Mass Index (BMI) survey among the study groups, most of the students main- 


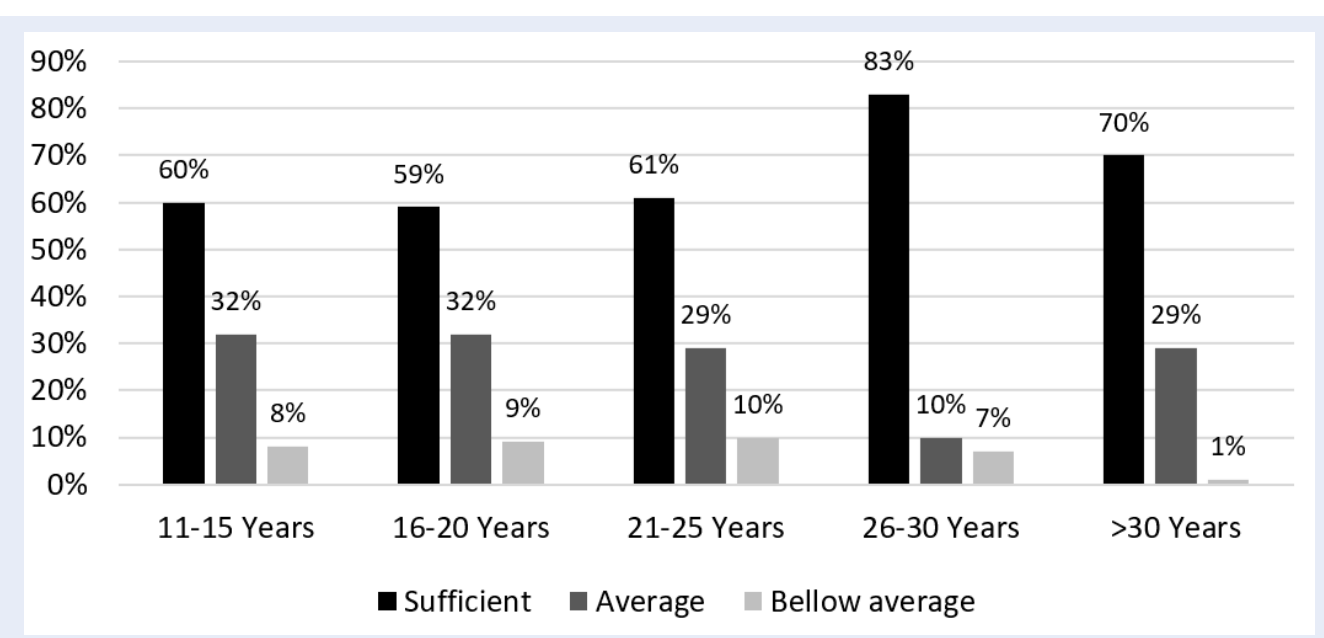

Figure 8: Percentages of Nutrition based awareness among the age groups.

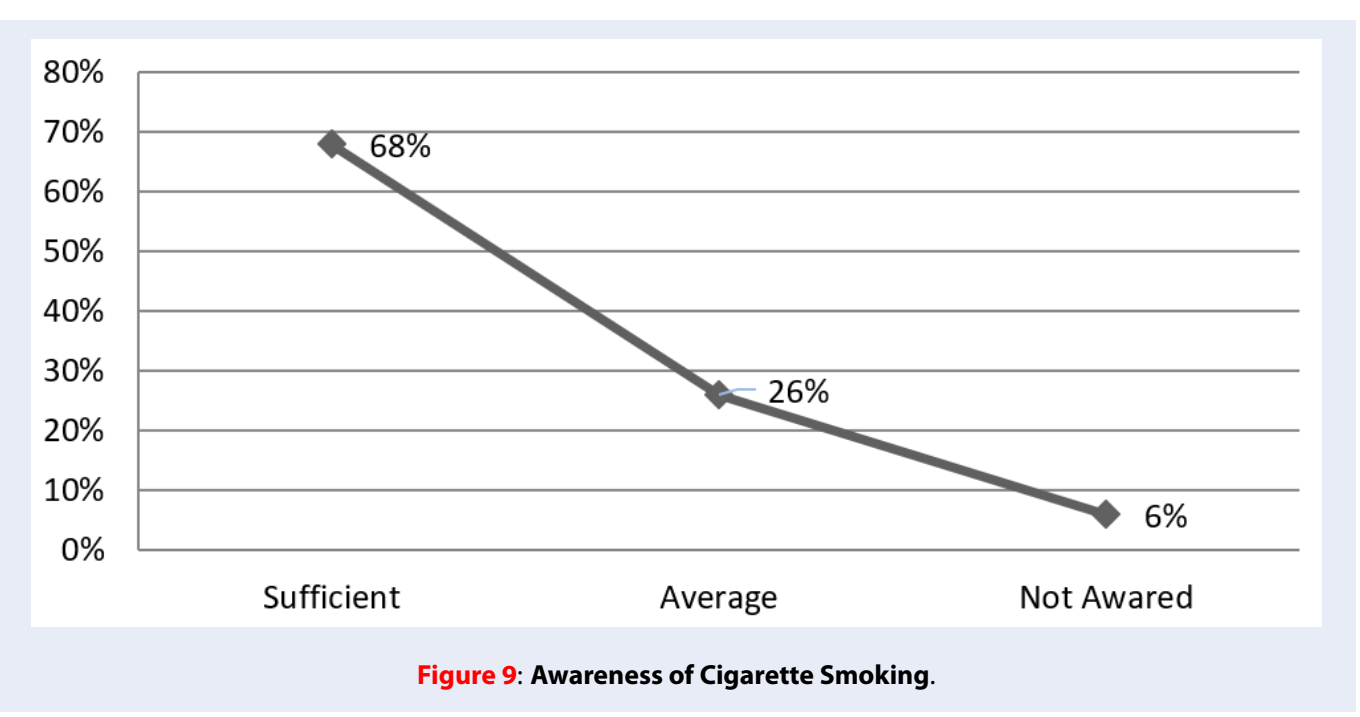

tained a normal body weight; the average percentage was $65 \%$ among all age groups. About $12 \%$ students were found under weight and $23 \%$ was found overweight on an average among the study groups. Normal BMI was observed in all age groups except 1115 years and $>30$ years, where $31 \%$ students were found underweight and 53\% students were found overweight individually. A study conducted earlier in Noakhali during 2016 showed that $70 \%$ students maintained normal body weight, $12 \%$ students were overweight, and $17 \%$ students were underweight ${ }^{43}$. Another study was carried out in Lebanon during 2008 and showed that overweight and obesity among male students were $37.5 \%$ and $12.5 \%$ respectively ${ }^{44}$. In our study, the maximum numbers of normal body weight were observed in 21-25 years of age group and 26-30 years of age group where the values were $80 \%$ and $79 \%$ respectively and the enrolled students in these age groups were more conscious about their Body Mass Index. As 53\% students were found overweight in students $>30$ years of age and $31 \%$ students were observed underweight in students of $11-15$ years of age, they might be less conscious about their food or nutrition intake, body weight and health status.

Fast food consumption among the study groups was examined in this study. About $50 \%$ students were found to consume fast foods occasionally, $11 \%$ students used to consume frequently and the rest of the students rarely consumed fast food. A study done earlier by Elif et al. revealed that $14.8 \%$ of students consumed fast foods once in a month, $18.8 \%$ of students 


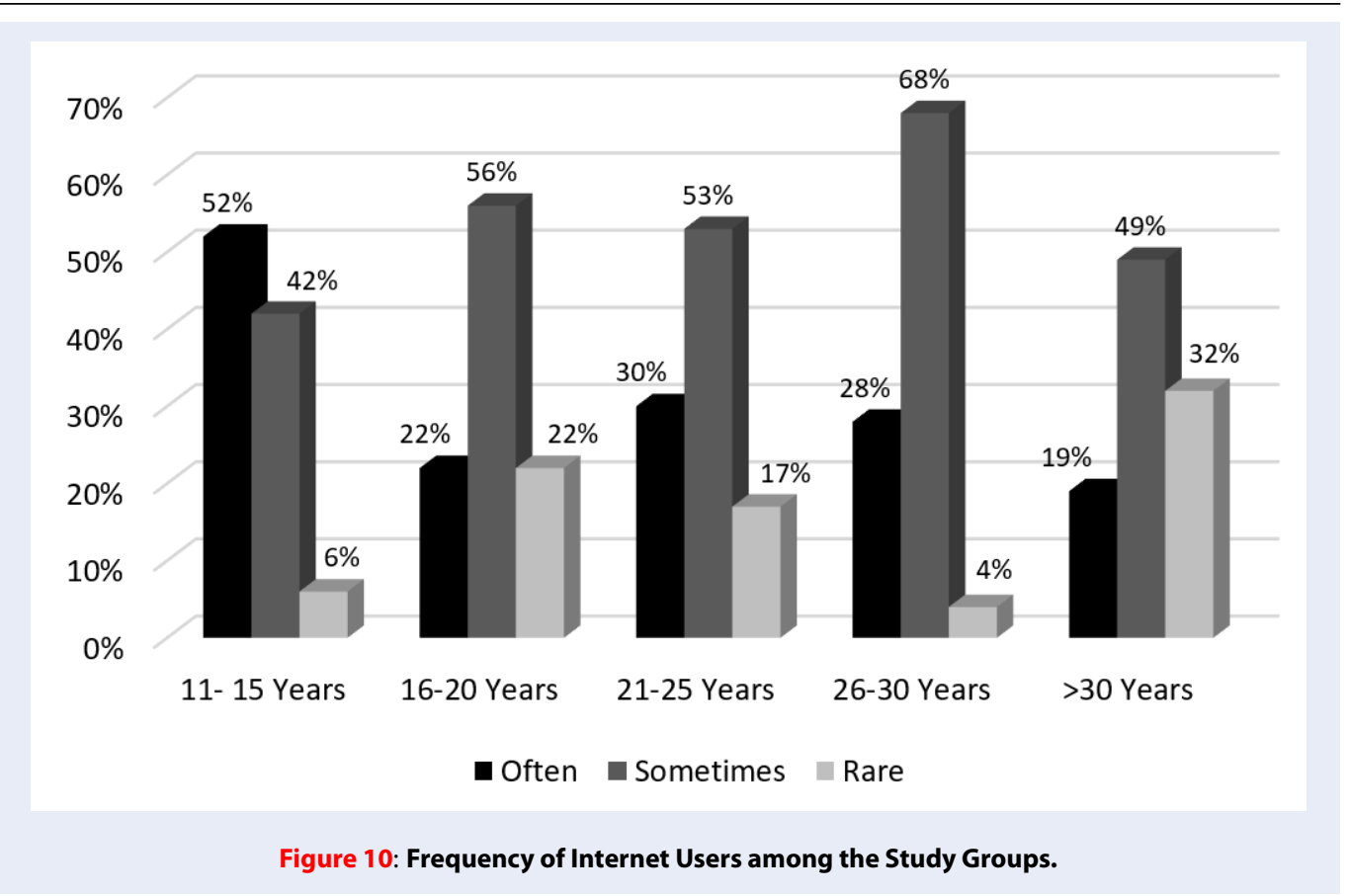

consumed two to four times in a month, $39.8 \%$ of students consumed 5 to 10 times in a month, $26.8 \%$ of students consumed more than 10 times in a month ${ }^{45}$. Comparatively, it can be said that most of the students liked to eat fast food occasionally in both studies. In fact our study conducted on student community and fast food consumption is expensive for them. Other important factors are that the primary level students are not allowed to take outdoor foods by their parents, hostel students' life styles are normal and below normal according to Bangladesh perspective. Study pressure, restrictions on hanging out with friends and availability of fast food shops near academic institutes are remarkable or unavoidable factors.

Fruits and vegetables provide valuable and essential elements for health such as dietary fibers, different types of vitamins (vit-A, B complex and C), carotenoids, glucosinoids, folic acids, and flavonoids ${ }^{46}$. In our study, we found that most of the students took fruits and vegetables regularly. A study earlier in Saudi Arabia by Hamdan et al. during 2016 found that $71.67 \%$ students consumed vegetables regularly in a week ${ }^{47}$. In our study, the average percentage was $58.20 \%$, who consumed fruits and vegetables regularly among all age groups. A comparative study shows that most of the students of all age groups were conscious about the importance of the fruits and vegetables.

In this study, we found a small percentage of students maintained regular balanced diet where the value was around $35 \%$ and a huge percentage of the students could not follow balanced diet regularly. Maybe they were not aware about the importance of balanced diet or they were not conscious enough. Another important thing is that in Bangladesh, most of the populations are living in the countryside, where low economy regions are present and availability of sufficient food and knowledge of balanced diet are maternally dependent. Maintaining balanced diet among students living in distant places and away from home and in hostels were not satisfactory. This might be due to limited awareness or consciousness. Maintaining a healthy diet or balanced diet regularly helps to minimize malnutrition and reduces the chances of non-communicable diseases. The important causes of changing dietary pattern are increased production of processed foods, rapid urbanization and changing life style. A healthy diet includes fruits, vegetables, legumes, nuts, proteins and grains. Eating required an amount of fruits and vegetables per day reduces the risk of noncommunicable Diseases (NCD) ${ }^{48}$.

Among all age groups, most of the students had been associated with physical activities. About $63 \%$ of students of 11-15 years of age did physical activities regularly in our study. In students of 16-20 years of age, $57 \%$ students, in $21-25$ years of age groups - 53\% students, in $26-30$ years of age groups - $60 \%$ students, and in $>30$ years student's group - $51 \%$ students found who had been doing physical activities regularly. An earlier study in Saudi Arabia by Hamdan et al. in 2016 re- 
vealed that, $29 \%$ students maintained physical activities regularly, and $45.33 \%$ students maintained sometimes ${ }^{47}$. Another study showed that, $41.1 \%$ was inactive, $17.8 \%$ students were rarely active, $28.5 \%$ students were moderately active and $12.6 \%$ was highly active in physical activities ${ }^{10,11}$.

In our study we found that most of the students had nutritional awareness. About $83 \%$ was found in students in the 26-30 years of age, who were sufficiently aware about nutrition, $70 \%$ students were found who had nutritional awareness in $>30$ years of age groups of the students, $61 \%$ found in 21-25 years of age groups, $60 \%$ found in $11-15$ years of age groups, and the students who were between 16-20 years of age groups the percentage was 59\%. A study revealed that students who had physical education were more aware than other students ${ }^{49}$. Because researches showed that nutrition knowledge is related with their fields of study ${ }^{50,51}$. It might be useful to study the biology, food and nutrition related subjects and knowledge of food values, for which, student's nutrition awareness can be observed.

The majority of the study subjects were aware of the effects of cigarette smoking. Among all students, $68 \%$ students had knowledge about smoking related problems or health risks, and $26 \%$ students had a limited knowledge about the effects of smoking. Tobacco is one of the common risks for oral cancer ${ }^{52}$. A survey showed that, $58 \%$ tobaccos are being used by men and $42 \%$ by women ${ }^{53}$. World Health Organization (WHO) gives priority to relate tobacco and oral diseases emphasizes involving dental health professionals in tobacco control and cessation activities ${ }^{54,55}$. In our study cigarette smoking awareness percentage was satisfactory, and the probability of smoking related diseases might be reduced.

Using internet among students of 11-15 years was higher than others, and about 52\% students used internet regularly in this age group. The tendency of using internet was lower in students of $>30$ years of age, where only $19 \%$ students who used internet. The average percentage of occasional internet users was $53.60 \%$. An earlier study by Amanda et al. shows that $93 \%$ of teenagers of 12-17 years used internet, while adults are less likely to use internet ${ }^{56}$. A study showed that teenagers use internet higher than other ages due to their educational purpose, playing video games, listening to music, watching movies and passing their leisure periods.

\section{CONCLUSIONS}

This study was conducted among students' community selected randomly from primary, secondary, higher secondary and university students of Chattogram regions. The objectives of this study were to reveal the awareness regarding health issues among students' community by collecting information about BMI, fast food habits, nutrition, maintaining balanced diet, fruits and vegetables consumption, physical activity, smoking and using of internet.

From this study, we can conclude that among the students, most of them maintained normal body weight. An average of $23.20 \%$ of students was overweight and some of the teenagers were underweight. Awareness should be raised higher among teenagers than other age groups.

The present research shows only $11 \%$ students consumed fast food and most of the students consumed rarely. It seems that they were aware about the effects of regular fast food diet. In this study, we found that the $>30$ age group students were more aware of nutrition than other groups.

Teenagers were less conscious about nutritional awareness and, as a result, some of them were underweight. Maintenance of balanced diet is good for health. University students were more conscious and most of them maintained balanced diet.

It was also observed that teenagers did not maintain balanced diet regularly. Most of the higher secondary and undergraduate students take fruits and vegetable regularly. Awareness should be raised among students about the benefits of taking fruits and vegetables.

The $>30$ age group of students practiced physical activities more regularly than teenagers.

In our study, it was noticed that most of the students (about 68\%) were aware about the harmful effects of cigarette smoking.

Using internet is important in the current world. It helps the students in education, research, social communication and entertainment. Most of the teenagers used internet compared to other age groups we found in our study.

Awareness by providing correct information about balanced diet, nutrition, regular physical activities, fast food consumption, use of internet and effects of smoking should be included in the educational curricula in academic places. Students enrolled in this study were from different areas across Chattogram regions of Bangladesh, where, students might stay at home with parents, other relatives in distant places and in academic hostels. The students were from different religious beliefs, culture, ethnicity, and areas. Based on the mentioned categories of the students, their food choices, daily habits, lifestyles and health awareness could be different. 
Initiatives should be taken by social media, work place programs, different activities by health care and nonhealth care professionals, public involvement in programs by government or NGOs, motivational programs in different health issues in academic institutes. These activities are highly recommended improving the health status among students, who are the ultimate future boatmen of a nation.

\section{ACKNOWLEDGMENTS}

All of the authors have equal contribution to this research. The research was done under the direct supervision of Mohammed Jahedul Islam. Result analysis and manuscript writing were done by Abdullah Al-Mamun, Pabitra Debnath, Farida Siddika and directed by Mohammed Jahedul Islam.

\section{FINANCIAL SUPPORT}

There was no financial support for conducting the research.

\section{CONFLICTS OF INTEREST}

There are no conflicts of interest among authors.

\section{REFERENCES}

1. Media Centre, Obesity and overweight. 2018, http://www.wh o.int/mediacentre/factsheets/fs311/en/.

2. FAO/WHO, 2002 Human vitamins and minerals requirements, Report of a joint, FAO/WHO expert consultation, Rome.

3. Nojomi M, Najamabadi S. Obesity among university students, Tehran, Iran. Asia Pac J Clin Nutr. 2006;15(4):516-20. PMID: 17077068.

4. Mendez MA, Popkin BM, Jakszyn P, Berenguer A, Tormo MJ, Sanchéz MJ, et al. Adherence to a Mediterranean diet is associated with reduced 3-year incidence of obesity. J Nutr. 2006;136(11):2934-8. PMID: 17056825. Available from: 10. 1093/jn/136.11.2934.

5. Farrell SW, Kampert JB, Kohl HW, Barlow CE, Macera CA, Paffenbarger RS, et al. Influences of cardiorespiratory fitness levels and other predictors on cardiovascular disease mortality in men. Med Sci Sports Exerc. 1998;30(6):899-905. PMID: 9624649.

6. Warburton DE, Nicol CW, Bredin SS. Health benefits of physical activity: the evidence. CMAJ. 2006;174(6):801-9. PMID: 16534088. Available from: 10.1503/cmaj.051351.

7. Slavin JL, Lloyd B. Health benefits of fruits and vegetables. Adv Nutr. 2012;3(4):506-16. PMID: 22797986. Available from: 10.3945/an.112.002154.

8. Atiqua S, Savita A. A comparative study on eating behaviour of public school and Government school children of Lucknow city. Adv Res J Soc Sci. 2016;7(2):279-83. Available from: 10. 15740/HAS/ARJSS/7.2/279-283.

9. Lissau I, Overpeck MD, Ruan WJ, Due P, Holstein BE, Hediger ML. Health Behaviour in School aged Children Obesity Working Group. Body mass index and overweight in adolescents European countries, Israel, and the United States. Arch Pediatr Adolesc Med. 2004;1:27-33. PMID: 14706954. Available from: 10.1001/archpedi.158.1.27.

10. Mazzeo RS, Cavanagh P, Evans WJ, Fiatarone M, Hagberg J, McAuley E, et al. American College of Sports Medicine Position Stand. Exercise and physical activity for older adults. Med Sci Sports Exerc. 1998;30(6):992-1008. PMID: 9624662.
11. Payne S, Townsend N, Foster C. The physical activity profile of active children in England. Int J Behav Nutr Phys Act. 2013;10(1):136. PMID: 24341402. Available from: 10.1186/ 1479-5868-10-136.

12. Food Nations: Selling Taste in Consumer Societies. New York (NY): Routledge; 2002.

13. Hertzler AA, Frary RB. Family factors and fat consumption of college students. J Am Diet Assoc. 1996;96(7):711-4. PMID: 8675917. Available from: 10.1016/S0002-8223(96)00195-2.

14. Cupisti AM, Downs CL. Dumke and Neiman DC. Nurition supplementation practice and nutrition knowledge of marathon runners. Med Sci Sports Exerc. 2004;36(5):349-50.

15. Kaushik JS, Narang M, Parakh A. Fast food consumption in children. Indian Pediatr. 2011;48(2):97-101. PMID: 21378418. Available from: 10.1007/s13312-011-0035-8.

16. Ansari WE, Stock C, Mikolajczyk RT. Relationships between food consumption and living arrangements among university students in four European countries - a cross-sectional study. Nutr J. 2012;11(1):28-34. PMID: 22531503. Available from: 10.1186/1475-2891-11-28.

17. Col MA, Col RK. Junk Food Consumption and Knowledge about its III Effects among Teenagers: A Descriptive Study. Int J Sci Res (Ahmedabad). 2013;4(6):1133-6.

18. Steinmetz KA, Potter JD. Vegetables, fruit, and cancer. I. Epidemiology. Cancer Causes Control. 1991;2(5):325-57. PMID: 1834240. Available from: 10.1007/BF00051672.

19. Block G, Patterson B, Subar A. Fruit, vegetables, and cancer prevention: a review of the epidemiological evidence. Nutr Cancer. 1992;18(1):1-29. PMID: 1408943. Available from: 10. 1080/01635589209514201.

20. Margetts BM, Thompson R, Duffy S on behalf of theNutritional Epidemiology Working Group on Diet and Cancer. A Review of the Epidemiological Literature Linking Fruit and Vegetable Consumption to Risk of Cancer 1994.

21. Ness AR, Powles JW. Fruit and vegetables, and cardiovascular disease: a review. Int J Epidemiol. 1997;26(1):1-13. PMID: 9126498. Available from: 10.1093/ije/26.1.1.

22. Bashed MA, Gazi MA, Kabir MA, Abul QA. Male Infertility in Bangladesh: What Serve Better-Pharmacological Help or Awareness Programme? Int J Pharmacol. 2012;8(8):687-94. Available from: 10.3923/ijp.2012.687.694.

23. Orbiclinic, 2011. Infertility in men is increasing. San Francisco, CA 94104, USA.

24. Curtis KM, Savitz DA, Arbuckle TE. Effects of cigarette smoking, caffeine consumption, and alcohol intake on fecundability. Am J Epidemiol. 1997;146(1):32-41. PMID: 9215221. Available from: 10.1093/oxfordjournals.aje.a009189.

25. Chia SE, Lim ST, Tay SK, Lim ST. Factors associated with male infertility: a case-control study of 218 infertile and 240 fertile men. BJOG. 2000;107(1):55-61. PMID: 10645862. Available from: 10.1111/j.1471-0528.2000.tb11579.x.

26. Gaur DS, Talekar M, Pathak VP. Effect of cigarette smoking on semen quality of infertile men. Singapore Med J. 2007;48(2):119-23. PMID: 17304390.

27. Chou WY, Hunt YM, Beckjord EB, Moser RP, Hesse BW. Social media use in the United States: implications for health communication. J Med Internet Res. 2009;11(4):e48. PMID: 19945947. Available from: 10.2196/jmir.1249.

28. Vance K, Howe W, Dellavalle RP. Social internet sites as a source of public health information. Dermatol Clin. 2009;27(2):133-6. PMID: 19254656. Available from: 10.1016/j.det.2008.11.010.

29. Thackeray R, Neiger BL, Hanson CL, McKenzie JF. Enhancing promotional strategies within social marketing programs: use of Web 2.0 social media. Health Promot Pract . 2008;9(4):338-43 .

30. Centers for Disease Control and Prevention (CDC). 2009-03-31. Social Media at CDC. http://cdc.gov/socialmedia/. .

31. Norman CD, Mclntosh S, Selby P, Eysenbach G. Webassisted tobacco interventions: empowering change in the global fight for the public's (e)Health. J Med Internet Res. 2008;10(5):e48. PMID: 19033147. Available from: 10.2196/ jmir.1171. 
32. Wangberg SC, Andreassen HK, Prokosch HU, Santana SM, Sørensen T, Chronaki CE. Relations between Internet use, socio-economic status (SES), social support and subjective health. Health Promot Int. 2008;23(1):70-7. PMID: 18083686. Available from: 10.1093/heapro/dam039.

33. Thivel D, Chaput JP. [Food consumption in children and youth: effect of sedentary activities]. Rev Epidemiol Sante Publique. 2013;61(4):399-405. PMID: 23849298. Available from: 10.1016/j.respe.2013.01.098.

34. Chaput JP, Klingenberg L, Astrup A, Sjödin AM. Modern sedentary activities promote overconsumption of food in our current obesogenic environment. Obes Rev. 2011;12(5):e1220. PMID: 20576006. Available from: 10.1111/j.1467-789X. 2010.00772.x.

35. Temple JL, Giacomelli AM, Kent KM, Roemmich JN, Epstein LH. Television watching increases motivated responding for food and energy intake in children. Am J Clin Nutr. 2007;85(2):35561. PMID: 17284729. Available from: 10.1093/ajcn/85.2.355.

36. Laranjo L, Arguel A, Neves AL, Gallagher AM, Kaplan R, Mortimer $\mathrm{N}$, et al. The influence of social networking sites on health behavior change: a systematic review and metaanalysis. J Am Med Inform Assoc. 2015;22(1):243-56. PMID: 25005606. Available from: 10.1136/amiajnl-2014-002841.

37. Menon IS, Sharma MK, Chandra PS, Thennarasu K. Social networking sites: an adjunctive treatment modality for psychological problems. Indian J Psychol Med. 2014;36(3):260-3. PMID: 25035548. Available from: 10.4103/0253-7176.135374.

38. Moreno MA. JAMA pediatrics patient page. Transition of care from pediatric to adult clinics. JAMA Pediatr. 2013;167(7):684. PMID: 23817857. Available from: 10.1001/jamapediatrics.2013. 2657.

39. Rice SM, Goodall J, Hetrick SE, Parker AG, Gilbertson T, Amminger $G P$, et al. Online and social networking interventions for the treatment of depression in young people: a systematic review. J Med Internet Res. 2014;16(9):e206. PMID: 25226790. Available from: 10.2196/jmir.3304.

40. Valle CG, Tate DF, Mayer DK, Allicock M, Cai J. A randomized trial of a Facebook-based physical activity intervention for young adult cancer survivors. J Cancer Surviv. 2013;7(3):35568. PMID: 23532799. Available from: 10.1007/s11764-0130279-5.

41. Kautiainen S, Koivusilta L, Lintonen T, Virtanen SM, Rimpelä A. Use of information and communication technology and prevalence of overweight and obesity among adolescents. Int J Obes. 2005;29(8):925-33. PMID: 15925961. Available from: 10.1038/sj.ijo.0802994.

42. Afshin A, Babalola D, Mclean M, Yu Z, Ma W, Chen CY, et al. Information Technology and Lifestyle: A Systematic Evaluation of Internet and Mobile Interventions for Improving Diet, Physical Activity, Obesity, Tobacco, and Alcohol Use. J Am Heart
Assoc. 2016;5(9):e003058. PMID: 27581172. Available from: 10.1161/JAHA.115.003058.

43. Karmakar P, Jahan N, Banik S, Das A, Rahman KA, Kundu SK et al. Food Habits, Obesity and Nutritional Knowledge among theUniversity Students in Noakhali Region of Bangladesh: Across Sectional Study. J Food Nutr Disord. 2016;5:4.

44. Yahia N, Achkar A, Abdallah A, Rizk S. Eating habits and obesity among Lebanese university students. Nutr J. 2008;7(1):32. PMID: 18973661. Available from: 10.1186/1475-2891-7-32.

45. Handan OA. 50.Elif AE, Handan OA. Factors Influencing Young Consumers' Preferences of Domestic and International Fast Food Brands.

46. Steinmetz KA, Potter JD. Vegetables, fruit, and cancer. II. Mechanisms. Cancer Causes Control. 1991;2(6):427-42. PMID: 1764568. Available from: 10.1007/BF00054304.

47. Hamdan Mohammed Al-Shehri, Awad Mohammed AlQahtani, Ibrahim Ahmed Shaikh, Moaiah Ali Hassan, Nasser Saeed Al-Qahtani, Ali M Al-Qahtani, Mosab A Alabas, Assessment of lifestyle and eating habits among undergraduate students in Najran University, Najran, Saudi Arabia, December 01, 2016.

48. Healthy diet. WHO.2018 http://www.who.int/mediacentre/fa ctsheets/fs394/en/.

49. Ali B, Mohsen E. Mohammad, Kazem R. A Study of Nutrition Knowledge, Attitudes and Food Habits of College Students. World Appl Sci J. 2011;15(7):1012-7.

50. Azizi M, Rahmani NF, Malaee M, et al. A study of Nutritional knowledge and attitudes of elite College Athletes in Iran. Braz J Biom. 2010;4(2):105-12.

51. Georgia S, Guldan YW, Lin Y. M. Zhao D.P. Xiang, L. Yang, F. Long. Evaluation of a nutrition education activity for medical student in, china. Asia Pac J Clin Nutr. 1993;2:71-6. PMID: 24352102.

52. Warnakulasuriya S. Global epidemiology of oral and pharyngeal cancer; 2008. Available from: 10.1016/j.oralomncology. 2008.06.002.

53. Impact of tobacco-related illnesses in Bangladesh. Dhaka: World Health Organization Press; 2005.

54. Watt RG, Daly B, Kay EJ. Prevention. Part 1: smoking cessation advice within the general dental practice. Br Dent J. 2003;194(12):665-8. PMID: 12830185. Available from: 10 1038/sj.bdj. 4810266 .

55. Organization WH. Code of practice on tobacco control for health professional organizations. Geneva, Switzerland: WHO Informal Meeting on Health Professionals and Tobacco Control; 2004.

56. Amanda L, Kristen P, Aaron S, Kathryn Z. Social media and mobile internet use among teens and young adults. Pew internet \& American life project. 